\title{
DEMOCRACIA: ¿RAZONES O PASIONES?
}

\section{Graciela Vidiella*}

Resumen: Según Chantal Mouffe, las concepciones deliberativas de la democracia desconocen el fenómeno político; esto se pone manifiesto en la pretensión de alcanzar un consenso racional que niega el conflicto, elemento insoslayable de la política. Otro error que les atribuye es privilegiar la razón sobre los componentes pasionales al considerar la motivación de las acciones. Como alternativa propone la democracia radical centrada en las ideas de "hegemonía", en la oposición nosotros-ellos y en la importancia de las pasiones en la política. Este artículo sostiene, primero, que la democracia deliberativa puede afrontar con éxito cada una de estas críticas; segundo, a partir de realizar una reconstrucción de los elementos normativos que contiene el pluralismo agonista, argumenta que fracasa en su intención de ofrecerse como una alternativa al estatus-quo de la democracia liberal ya que disuelve la validez en la facticidad.

Palabras clave: deliberación, consenso argumentativo, conflicto, motivación, hegemonía.

Abstract: According to Chantal Mouffe, deliberative conceptions of democracy reject the political phenomenon. This is evident when a rational consensus to deny the conflict -politically unavoidable- is supported. Another error she also underlines is to privilege rational more than emotional elements in order to consider actions motivation. As an alternative she proposes radical democracy centered on the one hand at the idea of "hegemony", according to the opposition us-them and in the other at the passions involved in politics. The author maintains that deliberative democracy can face successfully each one of those critics. After reconstructing the normative elements that radical democracy contains, the argument proves that it fails in the pretention to be an alternative to liberal democracy status-quo since it dissolves validity in facticity.

Doctora en Filosofía por la Universidad de Buenos Aires. En la actualidad es Profesora Titular de Ética en la Universidad Nacional del Litoral y Profesora Adjunta de la misma materia en la Universidad Nacional de La Plata. Se especializa en temas de ética y filosofía política contemporáneas. Dirección electrónica: gravidiella@gmail.com. 
Key words: deliberation, argumentative consensus, conflict, motivation, hegemony.

En la tradición del pensamiento democrático conviven en tensión dos modos de entender la política; uno de ellos pone el acento en la irreconciliable pluralidad de intereses, en la hipótesis del conflicto y en el escaso apego y capacidad que suele manifestar el ciudadano medio para involucrarse en la cosa pública; el otro, en la idea de bien común, en la participación ciudadana y en la búsqueda de consensos. Para el primero de estos modos, la legitimidad del sistema democrático reside en la institucionalización de mecanismos que aseguren la expresión y representación de los intereses en pugna. En el segundo, la idea de legitimidad se centra en la deliberación de los ciudadanos y, para decirlo en términos de Kant, en el uso público de la razón.

El primer modo concentró el interés teórico desde mediados del siglo XX a partir de la recepción que tuvo el influyente libro Capitalismo, Socialismo y Democracia, que el economista austríaco Joseph Schumpeter publicó en 1942 y en el que formula lo que Macpherson ${ }^{1}$ denominó el modelo de la democracia de mercado -también conocida como democracia agregativa-. Dicho modelo está organizado en torno a las nociones de "pluralismo", "equilibrio de intereses", "autointerés" y "satisfacción de preferencias", bases del sistema democrático entendido exclusivamente como un mecanismo de legitimación de la lucha que entablan los líderes políticos en su competencia por el voto de la ciudadanía. A partir de la década del setenta del siglo anterior, la democracia liberal -tanto en su sistematización teórica como en su práctica institucional- no ha dejado de ser objeto de múltiples críticas: se la acusa de reducir la democracia a un procedimentalismo insubstancial que quita legitimidad a las decisiones políticas, de relegar la participación de la ciudadanía al momento del voto y de este modo provocar su

1 Macpherson, C. B., The Life and Times of Liberal Democracy. Oxford, Oxford University Press, 1977. 
alejamiento del espacio público. Así se produce un círculo vicioso, porque esta retirada favorece el desinterés, los representantes gubernamentales se aíslan de los ciudadanos a los que representan, y ello incrementa el toma y daca en los acuerdos políticos, el tráfico de influencias y los procesos de corrupción.

Entre las alternativas que confrontaron con el modelo agregativo se destacaron en su momento la democracia participativa, formulada por Carol Pateman ${ }^{2}$ y la strong democracy de Benjamin Barber ${ }^{3}$, pero fue a partir de los años noventa cuando comenzó a perfilarse -bajo el estímulo de la obra de Habermas y, en su vertiente explícitamente liberal, de la de Rawls-, una concepción deliberativa de la democracia intencionadamente normativa, centrada en la idea de razón pública, que, en los años sucesivos, fue consolidándose como la alternativa más potente ante las deficiencias de la democracia liberal.

Recogiendo antecedentes tan remotos como la democracia ateniense $O$, más cercanos en el tiempo, ciertos aspectos del republicanismo de Harrington y Rousseau, así como la defensa de la deliberación pública en la búsqueda de la verdad realizada por John Stuart Mill, los partidarios de la democracia deliberativa consideran que la pluralidad y el conflicto de intereses no tienen la última palabra en materia de decisión política; también es posible entenderla como una deliberación pública en la que los ciudadanos o sus representantes tienen disposición a dialogar para buscar consensos en pos del bien común.

Por otra parte, se ha ido conformando una tercera alternativa, fuertemente crítica tanto de la democracia liberal como del enfoque deliberativo. Si bien el pluralismo agonista -también conocido como democracia radical- concuerda con sus objeciones a la democracia liberal,

2 Pateman, C., Participation and Democratic Theory, Cambridge, Cambridge University Press, 1977.

3 Barber, B., Strong Democracy. Participatory Politics for a New Age, Berkeley and Los Ángeles, University of California Press, 1984. 
considera que la propuesta deliberativa se ha edificado sobre la base de una ignorancia profunda concerniente a la naturaleza de lo político, ignorancia que la condujo a construir una teoría ingenuamente idealista que termina disolviendo la política en la ética. Según Chantal Mouffe, promotora de esta perspectiva, este error tiene su origen en la crisis del marxismo y del consecuente abandono de la idea de lucha de clases como motor de la historia que condujo a muchos pensadores de la izquierda europea a adoptar el modelo liberal democrático, racionalista y universalista, que eliminó el antagonismo del campo de la política en pos de consensos ideales. Sin embargo, piensa la autora, este camino no sólo es engañoso sino también peligroso: en efecto, la identidad de la democracia occidental dependía, en gran parte, de lo que la diferenciaba del totalitarismo del bloque soviético; desaparecido éste, es necesario volver a definirla en concordancia con la nueva realidad, pero una teoría que desconoce que toda identidad se constituye por negación de una diferencia y propugna un universalismo que disuelve toda diferencia, se muestra incapaz de comprender las nuevas formas que asumen los conflictos en las democracias liberales, étnicas, religiosas, identitarias ${ }^{4}$.

Este trabajo se propone defender la democracia deliberativa de las objeciones realizadas por el pluralismo agonista. Para ello se comienza por presentar los aspectos salientes de la teoría deliberativa (I), luego se los confronta con las críticas realizadas por la democracia radical (II) y, por último, se realiza una evaluación de dichas críticas procurando mostrar que la democracia deliberativa está en condiciones de absorberlas (III).

I.

Para las concepciones deliberativas, la cuestión nodular de la teoría de la democracia concierne a la legitimidad política. Si la "voluntad del pueblo" conserva aún su significado simbólico, éste no se encuentra reflejado en la idea de legitimidad limitada a un consenso obtenido por la

4 Laclau, E. y Mouffe, C., Hegemonía y estrategia socialista, Buenos Aires, Fondo de Cultura Económica, 2006, pp. 15 y ss. 
regla de la mayoría que se aplica a la maximización de intereses en disputa. Como alternativa, la teoría deliberativa sostiene que las decisiones que atañen al ejercicio del poder son legítimas si pueden ser entendidas como el resultado de un proceso deliberativo basado en un libre intercambio de razones entre todos los afectados. Dicho en otros términos, quienes actúan en política deben presentar o responder a razones, o demandar que sus representantes lo hagan, con el propósito de justificar las leyes y las políticas públicas. La idea no es, claro está, que todas las decisiones políticas deban ser indefectiblemente el resultado de una deliberación -si la exigencia fuera ésta, se impugnarían las decisiones secretas que son facultad del poder ejecutivo en todo sistema democrático, o ciertas negociaciones llevadas a cabo por los distintos grupos políticos-, sino que los procedimientos de toma de decisión no deliberativos puedan defenderse en términos de deliberación pública.

Este modo de concebir la legitimidad ha convertido a la razón pública en el corazón normativo de la propuesta. De ella se formularon distintas versiones, algunas exclusivamente procedimentales, como las de Habermas y seguidores, otras con algún contenido sustantivo, como las de Rawls y Joshua Cohen; lo común a todas es postular la razón pública como una suerte de idea regulativa que funciona como un criterio contrafáctico de validación de procesos democráticos de decisión colectiva en general y del debate político en particular. En este sentido, una decisión política es legítima si puede ser objeto de acuerdo entre personas libres e igualmente capaces de aceptar la fuerza del mejor argumento ${ }^{5}$ en un procedimiento de deliberación pública llevado a cabo bajo condiciones de imparcialidad. Bajo esta luz se interpreta que el Estado sólo cumple con la demanda de igual respeto si puede justificar sus políticas de acuerdo con un proceso deliberativo de las características mencionadas; esto exige también que el contenido de las deliberaciones pueda ser comprendido por todos, de modo que todos puedan reconocer como razonables los

${ }^{5}$ Cohen, J. en J. Bohman and W. Rehg (ed), Deliberative Democracy: Essays on Reason and Politics, Cambridge, Massachusetts, London, The MIT Press, 1999, pp. 416424. 
argumentos aducidos -aunque no necesariamente acuerden con ellos-. De modo que, a diferencia de las concepciones agregativas, que basan la toma de decisiones colectivas en las preferencias formadas en el ámbito privado, la naturaleza pública y abierta del procedimiento deliberativo admite la posibilidad del cambio de preferencias ${ }^{6}$ bajo el supuesto de que las personas, en ciertas condiciones, estarán dispuestas a modificar sus puntos de vista y demandas iniciales si durante el proceso encuentran buenas razones para hacerlo. La hipótesis es que en los foros de deliberación adecuadamente construidos, los participantes puedan adquirir una perspectiva más amplia de los temas en discusión y desarrollar una disposición a tomar en cuenta las demandas de los demás y las consideraciones de bien público.

Claro es que la posibilidad de arribar a un consenso unánime en las democracias contemporáneas resulta extremadamente improbable, y la teoría deliberativa no desconoce esta circunstancia; en tal sentido, es inexacto afirmar que la votación, a la que suele verse como el gran momento de la democracia, apenas encuentra lugar en esta concepción; la decisión final de una deliberación dependerá, en muchos casos, del voto y de la regla de la mayoría. La diferencia con la posición agregativa es que se espera que aquellos ciudadanos que continúen en desacuerdo con las decisiones triunfantes se encontrarán en mejor disposición para aceptarlas porque fueron el resultado de un debate razonado; de modo que el voto es uno de los elementos del sistema democrático, aunque no ocupa un lugar privilegiado $^{7}$. Se infiere que un proceso deliberativo en el que los interesados puedan expresarse y perciban que sus demandas son tenidas en cuenta en razón de su propio valor y razonabilidad, hará más aceptable para las minorías circunstanciales un resultado desfavorable a sus expectativas que un proceso en que la decisión dependa exclusivamente de

'Elster, J. "The Market and the Forum: Three Varieties of Political Theory", en Bohman and W. Rehg (ed), op. cit., pp. 3-33.

${ }^{7}$ Knight, J. y Johnson, J. "Aggregation and Deliberation: On the possibility of Democratic Legitimacy”, en Political Theory, Vol. 22, N² 2, Mayo 1994, pp. 277296. 
negociaciones interesadas. Ésta sería la manera más justificada de hacer lugar a lo que Rawls denominó el factum del pluralismo. La posibilidad de discutir públicamente cuestiones controvertidas podría dar lugar a que los ciudadanos expresaran sus diferentes interpretaciones sobre los valores básicos de la libertad y la igualdad. En circunstancias de este tipo podría esperarse que los oponentes, luego de dar argumentos a favor de su posición y escuchar los de los demás, estarían dispuestos a poner entre paréntesis las posiciones más ríspidas en aras de continuar el diálogo político con la esperanza de llegar a un acuerdo o a posponer el debate en espera de una ocasión más propicia ${ }^{89}$. En pocas palabras, existe una apuesta a favor de que el proceso deliberativo pueda constituir una instancia de aprendizaje de ciudadanía democrática.

En síntesis, la democracia deliberativa construye su propuesta bajo el supuesto de una racionalidad comunicativa -aunque no necesariamente en su versión habermasiana- y sobre esta base justifica ciertas demandas morales a la política.

¿Utopía irrealista? ¿Optimismo incauto?

\section{II.}

Varias y heterogéneas son las influencias que ayudan a Chantal Mouffe a articular la concepción pluralista y agonista de la democracia, destinada a reformular el proyecto socialista en un tiempo en el que han ocurrido varias muertes: la del sujeto, la de los grandes relatos, la de la supremacía de la razón. Por ello, aunque Mouffe se identifica con la tradición marxista, abjura de sus categorías centrales: la lucha de clases, el proletariado como sujeto privilegiado de la historia, la determinación de la estructura económica sobre la superestructura, en fin, de toda categoría que posea resabios esencialistas $y$, como es natural, de toda idea de

${ }^{8}$ Gutman, A. y Thomson, D., Democracy and Disagreement, Harvard, The Belknap Press of Harvard University Press, 1996, pp. 134 y ss. 
teleologismo y necesariedad históricos. A cambio, su propuesta se nutre de aportes post-estructuralistas, en particular, de las ideas de deconstrucción e indecibilidad de Derrida a partir de las cuales recupera la noción gramsciana de hegemonía que convierte en la categoría central de análisis. Pero, asimismo, está convocado Carl Schmitt, de quien toma su concepción de lo político, así como el Wittgenstein de las Investigaciones Filosóficas, en particular, sus disquisiciones acerca de las prácticas y los juegos de lenguaje.

Mouffe comparte con los defensores de la democracia deliberativa la preocupación por consolidar y profundizar las instituciones democráticas, amenazadas por los efectos del modelo neoliberal. Temerosa de los efectos corrosivos de éste sobre el compromiso de la ciudadanía con los valores democráticos -en los últimos decenios se ha evidenciado un desinterés por los asuntos públicos y un descreimiento de la política y los políticos-, considera de vital importancia encontrar caminos que ayuden a promover la adhesión a dichos valores ${ }^{10}$. Sin embargo, el hilo de Ariadna que señale el camino permanecerá oculto si, en lugar de formular una teoría política correcta, que contribuya a afianzar la práctica democrática, se persiste en perseguir quimeras, como hace la concepción deliberativa.

Como ya se dijo, el corazón del agonismo pluralista se encuentra en la idea schmittiana ${ }^{11}$ del fenómeno político y en la teoría de la hegemonía elaborada por Antonio Gramsci. Schmitt concibe lo político como un campo de perpetuo e ineliminable antagonismo dominado por la siempre irreductible oposición amigo-enemigo; un "nosotros" que se constituye por oposición a un "ellos"; por su propia naturaleza lo político rechaza cualquier posibilidad de consenso que no sea excluyente, porque de otro modo se eliminaría el antagonismo y se disolvería la política. En conjunción con esto, el concepto de hegemonía es la categoría de que se

10 Mouffe, Ch., "Deliberative Democracy or Agonistic Pluralism", Reihe Politikwissenschaft. Political Science Series, $\mathrm{N}^{\circ} 72$, pp. 1-17.

11 Schmitt, C., The Concept of the Political, 1996, Chicago-London, University of Chicago Press, 1996. 
vale Mouffe tanto para explicar las luchas sociales como para orientar la praxis hacia la articulación de un nuevo proyecto hegemónico de la izquierda que dispute el poder a la hegemonía imperante. El aporte teórico del revolucionario italiano al campo marxista consistió, fundamentalmente, en mostrar la gran relevancia que posee el dominio ideológico -impuesto a través de los medios de comunicación, la educación y las instituciones religiosas- y su capacidad para inhibir el potencial revolucionario del proletariado $^{12}$; a la luz de esta idea, la hegemonía puede entenderse como el liderazgo intelectual y moral que ejerce la clase que controla el aparato del Estado. El desafío para Gramsci residía en comprender cómo puede el proletariado $-\mathrm{o}$, en general, una clase subalterna-, convertirse en clase dirigente y disputar el poder hegemónico. A criterio de Mouffe, el defecto de esta idea de hegemonía es su deuda con una noción esencialista de sujeto: la clase obrera como conductora del proceso revolucionario; sin embargo, las herramientas deconstructivas permiten disolverla: el lugar del sujeto lo ocupan ahora las "posiciones de sujeto" sin referencia a ningún centro; no existen sujetos predeterminados de la acción social ni identidades necesarias; estas "posiciones de sujeto" pueden integrarse, de manera precaria, en "prácticas articulatorias"13 que constituyen el campo donde puede emerger una nueva hegemonía. La hegemonía, que sigue siendo la clave para analizar los procesos políticos y sus luchas, se entiende como una articulación discursiva de normas, valores y redescripciones de una "realidad" siempre contingente e inestable. Así, todo orden político es la expresión de una hegemonía, es decir, de un patrón específico de relaciones de poder que ha logrado imponerse, aunque -y ésta es, quizá, la mayor diferencia con Gramsci-, imposible de ser referida algún punto privilegiado del orden social.

12 Gramsci, A., Antologia, México, Siglo XXI, 1970.

13 Una práctica articulatoria consiste en la constitución de un sistema organizado que relaciona elementos heterogéneos antes disgregados y dispersos. Cuando distintas prácticas se enfrentan de modo antagónico y las fronteras que las separan son inestables y fluctuantes puede surgir una articulación hegemónica. (Laclau, E. y Mouffe, Ch., op. cit., p. 179). 
Lo expuesto permite comprender la dirección de las críticas de Mouffe a la democracia deliberativa.

El control racional al que los deliberativistas someten el debate político, expresado en la idea de razón pública, refleja un supuesto errado que consiste en privilegiar la razón sobre los componentes afectivos y pasionales que motivan la acción humana en general y la acción política en particular. La alternativa al modelo agregativo no es reemplazar la razón estratégica por alguna variante de la razón comunicativa. La tarea de buscar argumentos que ninguna persona racional podría rechazar para justificar la superioridad de la democracia liberal es una tarea tanto inútil como engañosa: inútil porque cualquier pretensión de validez universal está condenada al fracaso; es Wittgenstein y no Habermas quien puede ayudar en la elaboración de una teoría y práctica correctas de la democracia. En efecto, las instituciones de la democracia liberal deben ser entendidas como las que definen un posible juego de lenguaje político entre otros, y no como la opción más racional. Los procedimientos de la democracia sólo existen como conjuntos complejos de prácticas que están inscriptas en una forma de vida compartida, y sólo así pueden ser defendidos ${ }^{14}$; por ello es erróneo plantearlos como reglas que se justifican en base a principios -sean los de justicia que Rawls deriva de la posición original, o el principio de universalización de Habermas-, de los que se infiere también su forma correcta de aplicación. La estrategia argumentativa de los defensores de la democracia deliberativa es engañosa porque la pretensión de lograr un consenso totalmente inclusivo conduce a la negación del pluralismo.

En efecto, estas visiones filo-kantianas de la política pretenden absorber la diferencias bajo el requerimiento de la racionalidad o de las razones morales, pero de este modo sólo se consigue disimular la exclusión bajo el manto unificador de la racionalidad; esto conduce a descartar temas y modalidades expresivas del debate público, de modo que éste termina negándose a sí mismo: los valores y formas de vida particulares que se presentan como impedimento, constituyen la condición

${ }^{14}$ Mouffe, Ch., The Democratic Paradox, London-New York, Verso, 2000, p. 63. 
de posibilidad del debate; quitados ellos, ¿sobre qué se discutiría?. Los desacuerdos en política no pueden dirimirse racionalmente porque son desacuerdos sobre valores, o sobre los modos de interpretar los valores; en el caso de la política democrática, sobre cómo interpretar la igualdad y la libertad.

De estas inocultables antipatías hacia cualquier forma de racionalismo resulta el papel privilegiado que el pluralismo agonista otorga a las pasiones en el sostenimiento de la democracia; en efecto, en lugar de eliminar las pasiones de la esfera pública, sostiene Mouffe, debe "proveerse el terreno en el que ellas puedan ser movilizadas alrededor de objetivos democráticos a fin de que el antagonismo se convierta en agonismo"15.

Es comprensible, entonces, que este encuadre teórico rechace la idea de consenso racional sin exclusión, propuesto por los partidarios de la deliberación, como algo conceptualmente imposible, en tanto se está desconociendo que las identidades se construyen siempre por exclusión de lo otro exterior que, en el campo de lo político, está representado por la constitución de un "nosotros" por exclusión de un "ellos", ambos lábiles e inestables, capaces de disolverse y de volver a reunirse en otros agrupamientos, en los que no hay que descartar nuevas identificaciones que se estructuran reuniendo elementos que se excluían en las anteriores. Al buscar el consenso los teóricos deliberativos pretenden eliminar la disputa por el poder y, con ello, niegan la política disolviéndola en la ética.

\section{III.}

Antes de evaluar las críticas que realiza el pluralismo agonista a la democracia deliberativa conviene señalar que aquél parece pasar por alto la cuestión no menor de que la democracia deliberativa, en cualquiera de sus variantes, se asume de modo explícito como una teoría normativa. En

15 Mouffe, Ch., "Deliberative Democracy or Agonistic Pluralism", p. 16 (traducción propia). 
tanto, como sostendré más adelante, también la propuesta agonista posee componentes normativos, quizá no resulte superfluo precisar los rasgos propios de una teoría normativa. En primer lugar, no se limita a describir el funcionamiento de determinado objeto de estudio sino que contiene un polo de idealidad que pretende responder a la pregunta ¿cómo deberían ser las cosas? En segundo lugar, dicho polo organiza un conjunto de conceptos mediante principios que cumplen un rol legitimador. En nuestro caso, los conceptos definitorios de la democracia son el autogobierno a través de leyes, la libertad y la igualdad. En tercer lugar, una teoría normativa tiene una función crítica en relación con el statu quo $y$, en este sentido, permite orientar la práctica. Brevemente, un ideal normativo funciona como un criterio contra-fáctico de validación de procesos democráticos de decisión colectiva en general y del debate político en particular. Cierto es que, para decirlo al modo de Kant, resulta imprescindible que aquello que vale para la teoría también valga para la práctica y no ocurra que "cuando se pasa de la escuela al mundo uno advierte que ha perseguido ideales vacíos y sueños filosóficos"16. Una teoría normativa debe dar cuenta de la realidad sobre la que pretende aplicarse; dicho en otros términos, ninguna función cumpliría una teoría de la democracia que no recogiera las características que presentan las democracias actualmente existentes. Según mi parecer, contrario en este punto al de Mouffe, la concepción deliberativa cumple este requisito. En efecto, todas las propuestas asumen las características pluralistas de las sociedades contemporáneas y descartan un tipo de consenso basado en alguna idea sustantiva del bien común; en la política deliberativa el bien común debe interpretarse como el resultado, siempre provisorio y revisable, de los acuerdos obtenidos en la discusión pública sobre los diferentes temas.

En tanto las críticas del agonismo se focalizan en este último aspecto, creo necesario diferenciar las derivaciones del punto de vista rawlsiano del sostenido por Habermas y sus seguidores, porque considero que el segundo está en mejores condiciones de salir airoso de la

${ }^{16}$ Kant, I., Teoria y praxis, Buenos Aires, Leviatán, 2003, p. 11. 
confrontación. Aunque Mouffe reconoce la diferencia entre ambas vertientes, pasa por alto las consecuencias distintas que pueden extraerse de ellas. En efecto, es bien distinto defender una idea de razón pública con un contenido sustantivo, como hace Rawls ${ }^{17}$, que una exclusivamente procedimental, como la propuesta por Habermas. En tanto razón de los ciudadanos que se reconocen a sí mismos y a los demás como libres e iguales y que, como cuerpo colectivo, ejercen el poder político y final unos sobre otros ${ }^{18}$, la razón pública rawlsiana tiene la función de fijar los límites a los que debe atenerse la deliberación de los ciudadanos en el contexto de un pluralismo razonable. En los temas que le competen, los derechos constitucionales y de justicia básica, los ciudadanos deberían abstenerse de introducir propuestas y argumentos apelando a valores metafísicos, éticos o religiosos. Se ha criticado a Rawls que esta idea tan restringida de razón pública puede desdecir uno de los objetivos centrales del liberalismo político: dar cuenta del factum del pluralismo. De hecho, éste fue un punto importante de la polémica que sostuvo con Habermas ${ }^{19}$ y que daría razón a la objeción realizada por Mouffe. Pero, a mi modo de ver, no se aplica a una perspectiva exclusivamente procedimental, como la sostenida por Habermas, que permite pensar una razón pública conformada sólo por reglas de procedimiento tendientes a garantizar la imparcialidad y el triunfo de los mejores argumentos. La gran diferencia de esta perspectiva con la versión de Rawls es que todos los participantes tienen derecho a introducir el tema y punto de vista que deseen; en efecto, ésta es la prescripción de una de las reglas de la argumentación ${ }^{20}$ : ningún tema es excluido de antemano, es el propio debate el que va decantando las

${ }^{17}$ Rawls, J., Liberalismo político, México, Fondo de Cultura Económica, 1993. 18 Ibid., p. 205.

${ }^{19}$ Habermas, J. y Rawls, J. Debate sobre el liberalismo político, Barcelona, Paidós, 1998. ${ }^{20}$ Las reglas de la argumentación -formuladas por R. Alexy- son de tres clases: semánticas, pragmáticas y procedimentales. Ejemplos de ellas son: Ningún hablante debe contradecirse; todo hablante que aplica el predicado $F$ a un objeto $\boldsymbol{a}$ debe estar dispuesto a aplicar el predicado $F$ a todo objeto que se parezca a $\boldsymbol{a}$ en todos los aspectos importantes; etc. (cfr. Habermas, J., Conciencia moral y acción comunicativa, Barcelona, Ediciones Península, 1996, p. 110-113). 
razones provistas por los ciudadanos. Contra lo que Mouffe parece suponer, la idea de consenso argumentativo -que tiene, hay que remarcarlo, una función contra-fáctica- no necesita de la creencia en una validez universal en sentido absoluto; la teoría deliberativa rechaza una concepción completa y comprehensiva del acuerdo, cada compromiso es parcial y sujeto a revisión ante nuevas situaciones que lo pongan en entredicho. Del mismo modo que el pluralismo agonista, la teoría deliberativa presupone que los desacuerdos sobre valores suelen ser irreductibles. Como insistiera recurrentemente Rawls, una característica inapelable de las democracias contemporáneas es la coexistencia de personas que sostienen cosmovisiones del mundo, ideales de vida y valores que pueden resultar inconmensurables; de modo que sobre las "doctrinas comprehensivas" no cabe esperar consenso. Pero ello no significa que toda discusión política ponga en juego este tipo de valores o, que en caso de hacerlo - pensemos en temas muy conflictivos, como la legalización del aborto o de la eutanasia- no pueda esperarse que los ciudadanos se sientan motivados a entender las razones de aquellos con los que no coinciden.

Mouffe está en lo cierto al sostener que las diferencias profundas suelen ir acompañadas por pasiones que no pueden resolverse en la deliberación; entre otras razones, porque es verdad que las pasiones constituyen un aspecto importante de las identidades. Pero, justamente por ello, es dudoso que el mejor camino para profundizar las instituciones democráticas sea "movilizar las pasiones" dado que "un buen funcionamiento de la democracia reclama un vibrante choque de posiciones políticas" 21 . Un ejemplo de esto es el intenso debate ocurrido en Argentina en ocasión de la sanción de la ley que extendió el derecho a contraer matrimonio a personas del mismo sexo. En dicha oportunidad la entonces máxima autoridad de la iglesia católica, Cardenal Jorge Bergoglio, hizo pública una misiva que contenía las siguientes consideraciones: “(..) no seamos ingenuos, no se trata de una simple lucha política; es la pretensión destructiva al plan de Dios. (...) No se trata de un mero

${ }^{21}$ Mouffe, Ch., "Deliberative Democracy or Agonistic Pluralism”, p. 16. 
proyecto legislativo (éste es sólo el instrumento) sino de una 'movida' del padre de la mentira que pretende confundir y engañar a los hijos de Dios"22. Resulta bastante claro que estos argumentos están destinados a mover las pasiones de la grey católica para inducirla a afirmar su identidad ganando el espacio público en una cruzada de la fe a favor de la discriminación y de la lesión de la igualdad de derechos.

En términos generales, si bien resulta posible acordar con la idea del agonismo sobre la constitución de las identidades en la lucha política, hay que tener en cuenta que existen grupos que afirman la suya segregando a otros grupos. En honor a la verdad, Mouffe no desconoce esta circunstancia, pero, como su punto de vista no permite diferenciar formas razonables e irrazonables de afirmación de las identidades políticas, todo se reduce a observar qué pasiones salen triunfadoras de la contienda.

No es necesario ignorar el apego emocional que pueden tener los ciudadanos hacia los valores democráticos y la fuerza motivadora de éste en la acción política para defender el rol de la razón pública en la vida democrática. En el ejemplo que acabamos de considerar, lo razonable consiste en plantear el debate en términos de derechos, que es el modo en que lo han presentado diversos grupos y personas que también han ganado el espacio público, incluso católicos y otras agrupaciones religiosas, que se manifestaron tanto a favor como en contra de esta ley. ¿Por qué descartar de antemano que los interesados en el tema puedan aprender a dar y escuchar razones y estar dispuestos a cambiar su punto de vista si lo descubren errado? De este modo, la ciudadanía va reinterpretando, como quiere Mouffe, los valores de la democracia; en este caso, la igualdad. Es a este tipo de fenómenos que Habermas pretende dar cabida en su idea de esfera pública ${ }^{23}$, pensada como una doble vía que articula los poderes formales del Estado y la participación ciudadana. La mayor parte de las veces, las demandas por ampliación de los derechos,

22 Diario La Nación, 13/7/10.

${ }^{23}$ Habermas, J., The Structural Transformation of the Public Sphere. Cambridge (Mass.), The MIT Press, 1991. 
como en el ejemplo que estamos utilizando, provienen de agrupaciones de ciudadanos que han aprendido a articular sus reclamos en la esfera pública y han conseguido presentar sus intereses como universalizables. Si, en cambio, se niega de antemano que existan respuestas más razonables que otras se reduce la validez de cada respuesta a un ejercicio de poder político y a una disputa por la hegemonía. Descartar a priori la posibilidad de un consenso argumentativo no deja otra alternativa que la ofrecida por la democracia agregativa a la que el pluralismo agonista objeta: pugna de intereses, grupos de presión y regla de la mayoría como mecanismo de decisión.

Sin embargo, los agonistas se proponen profundizar la democracia liberal; cabe preguntarse, entonces, ¿qué tipo de acciones y decisiones contribuirían a esta transformación? Si la idea es democratizar los mecanismos de expresión -medios de comunicación, incluido el acceso a Internet, ONGs y otros espacios de expresión de la sociedad civil-, la idea de esfera pública habermasiana aporta un potencial crítico no desdeñable. Si se pretendiera, en cambio, reemplazar los mecanismos representativos por un modo directo de ejercicio y control del poder por parte del soberano, esto es, alguna variante rousseauniana, pero con ausencia de deliberación racional y de algún sucedáneo de la voluntad general, el resultado previsible sería la destrucción del orden institucional; pero seguramente éste no es el caso, porque los agonistas no abjuran de la democracia representativa. De manera que su planteo se dirige a una democratización de los canales de participación con el objetivo de multiplicar los espacios políticos como modo de combatir la concentración del poder, es decir, uno de los objetivos principales de la teoría deliberativa.

La última crítica a considerar es la referida a la negación de la naturaleza de lo político en tanto la concepción deliberativa, al proponer el consenso racional, niega el conflicto y el antagonismo. No creo, sin embargo, que la democracia deliberativa requiera impugnar las manifestaciones de lucha -huelgas, piquetes, tomas de fábricas- que hacen a la vida democrática y que suelen ser el medio del que disponen tanto las minorías como los sectores empobrecidos para hacerse escuchar. La 
exigencia normativa sólo demanda que los reclamos que motivan este tipo de expresiones puedan traducirse en razones, es decir, en intereses capaces de ser universalizados. Es verdad que existen quienes alegan que este tipo de conversión resulta imposible porque hay sistemas de creencias que son inconmensurables ${ }^{24}$; esto puede ser cierto, pero también lo es que muchos -si no la mayor parte- de los problemas que se discuten se basan en creencias compartidas y divergentes ${ }^{25}$, pero no inconmensurables. Claro está que este argumento no elimina la posibilidad de inconmensurabilidad entre algunos sistemas de creencias, pero no es posible saberlo antes de dialogar.

Más allá del debate entre democracia deliberativa y pluralismo agonista, creo que éste presenta un problema de consistencia en su planteo general. En efecto, pese a ser tan renuente a los modelos normativos, ofrece, aunque inarticulada, una propuesta normativa con la que enfrenta tanto a la visión agregativa como a la deliberativa -y también, aunque no nos hemos referido a ello, a la conversión republicana de antiguos comunitaristas ${ }^{26}$. Dicha propuesta puede presentarse del siguiente modo.

En primer lugar hay que remarcar lo ya dicho: al presentarse como una radicalización de la democracia liberal el pluralismo agonista defiende tanto los principios de libertad e igualdad como los derechos liberales, aunque no consiente con el significado que otorga a éstos la democracia liberal. Además - polemizando sobre todo con Rawls y Joshua Cohen- se niega a interpretar su contenido, alegando que esta tarea debe quedar librada al debate político.

El segundo componente normativo es la tarea de convertir al "enemigo" en "adversario", que se sustenta en la distinción entre "lo

${ }^{24}$ Lyotard, J-F., La condición postmoderna, Buenos Aires, Teorema, 1987, pp. 25 y ss. ${ }^{25}$ Benhabib, S., Las reivindicaciones de la cultura, Buenos Aires, Katz, 2006, pp. 178 y ss.

${ }^{26}$ Mouffe, Ch., El retorno de lo politico, Barcelona, Paidós, 1999, pp. 43 y ss. 
político" y "la política"27. Lo político recoge la dimensión de lucha y antagonismo propia de la sociabilidad humana, mientras que la política es la institución que apunta a ordenar y organizar la coexistencia; en este sentido, su papel consiste en desactivar el antagonismo. Así, el enemigo se convierte en adversario, esto es, en un "ellos" que tiene derecho a expresar sus ideas, un adversario al que "nosotros" combatiremos pero no destruiremos. De este modo, se recogen las enseñanzas del anti-liberal Carl Schmitt, pero empleadas para construir una forma política de liberalismo, que postula también la defensa de los derechos y del principio de libertad individual, pero no silencia el conflicto, ni el antagonismo, ni la decisión.

El tercer componente consiste en la expansión del pluralismo. En efecto, este "liberalismo radical", en tanto profundización de la revolución democrática que se inició con la revolución francesa, levanta como bandera el combate contra cualquier forma de subordinación y dominación. Según la lectura de Mouffe, en las democracias liberales contemporáneas este combate se expresa en las luchas de los nuevos movimientos sociales (feminismo, multiculturalismo, etc.), vistos como los grupos subordinados que disputan el actual orden hegemónico en pos de una democracia más pluralista. El programa de los demócratas radicales consiste en acompañar esta lucha con una teoría que contribuya a promover la pluralidad de formas de ser de la ciudadanía democrática y a la creación de instituciones que hagan posible seguir las reglas democráticas en una pluralidad de modos. De esto se sigue que la propuesta también presenta -como la deliberativa- una interpretación de los principios de libertad e igualdad: la primera es entendida como una exigencia de multiplicación de espacios públicos para expresar la pluralidad de creencias; en tanto que la igualdad es vista como el rechazo a cualquier forma de opresión y subordinación.

El problema es que la democracia agonista, a diferencia de la deliberativa, al diluir la legitimidad en la hegemonía, no consigue articular una perspectiva crítica del status quo. En efecto, si se disuelve toda

${ }^{27}$ Mouffe, Ch., "Deliberative Democracy or Agonistic Pluralism", p. 15. 
diferencia entre validez y facticidad la única legitimidad posible es la surgida del poder hegemónico, que es el poder exitoso. Pero esto atenta contra la razón de ser del agonismo: si se trata de construir una nueva hegemonía entre los grupos subordinados que dispute poder a la existente, debe admitirse que es necesario el diálogo y el intercambio de razones para coordinar las acciones colectivas y aunar intereses; ahora bien, si se rechaza cualquier versión de racionalidad comunicativa, si se privilegian las pasiones sobre las razones y los efectos perlocucionarios de la comunicación, entonces las mismas razones de los subordinados pierden fuerza. En síntesis, si todo se reduce a una disputa de hegemonías, ¿por qué habría que luchar contra la subordinación y la opresión? ¿Por qué habría que profundizar la democracia?

Recibido: 04/2013. Aceptado: 07/2013 